\title{
Analysis of aquaponics as an emerging technological innovation system
}

\author{
Bettina König, Judith Janker, Tilman Reinhardt, Morris Villarroel, Ranka Junge
}

Keywords:

Aquaponics

Aquaculture

Hydroponics

Sustainable food production Nutrient cycles Sustainable technologies

A B S T R A C T

Aquaponics is an approach of coupling two technologies: recirculation aquaculture (fish-farms) and hydroponics (soil-less cultivation of crops). While it is perceived as a way to contribute to more sustainable food systems, the technology is still in its infancy, with several challenges. This paper describes current conditions of development and identifies aspects that can promote or hinder future pathways. We focus our analysis on the EU, using Germany as an institutional case study, while also considering worldwide developments. We propose a framework to analyze aquaponics as an emerging technological innovation system at the interface between existing fish and plant production systems. The approach is explorative based on a literature review and interviews with experts. The main findings are that stakeholders have different views regarding the future development pathways, knowledge to manage complex systems in the long term is needed and it is still unclear how to design institutional conditions to deliver sustainable outcomes.

\section{Introduction} 1.1. The general context for the development of aquaponics:
challenges for innovative and sustainable food systems

There is general agreement that environmental, social and economic challenges drive the need for new and improved solutions for food production and consumption systems (food systems). Increasing food demands cannot be sustained by additional exploitation of natural resources and land on the production side. On the consumption side, transformations are needed to improve food security in developing countries and the healthiness and sustainability of western diets in developed nations (e.g. climate mitigating food consumption; Schuetze et al., 2008; Binz et al., 2010; Garnett, 2011; van der Goot et al., 2016; Ashley, 2016). In general, an increase in the production and consumption of fish and vegetables could be a way to improve the sustainability of food systems.

Food production within a sustainability corridor requires innovations exceeding traditional paradigms, acknowledging the complexity arising from sustainability (Leach et al., 2012; McIntyre et al., 2009; Pretty et al., 2010). However, there is a lack of strategic knowledge about how to direct further activities to develop those food production technologies while maintaining their promise of sustainability and potential solutions for urgent questions (Elzen et al., 2014).

One strategy to create more sustainable food systems is to change the way food is being processed (van der Goot et al., 2016). Another strategic approach is to change food production technologies themselves, ideally accompanied by changes in consumer behavior. Aquaponics is considered a promising example, potentially contributing to sustainability. The sustainable production of fresh fish and vegetables using intensive technological cycle systems and higher consumption is interesting for the scientific 
community (e.g. Junge et al., 2017), policy makers (e.g. Van Woensel and Archer, 2015) and entrepreneurs (e.g. Love et al., 2014; Joly et al., 2015).

The combined production of fish and annual plants has been practiced since ancient times. ${ }^{1}$ Yet modern day aquaponics, combining aquaculture and soil-less vegetable production (hydroponics) is still quite new and popular as an individual hobby in Europe and worldwide (Junge et al., 2017). It began to be used in the US and EU in the 1980s, however most fish and vegetables are still produced separately via aquaculture, hydroponics or land based vegetable production, in highly specialized technical, knowledge and capital-intensive production systems and value chains.

Currently, most aquaponics applications focus on research questions in aquaculture, hydroponics, water quality, microbiology and engineering. Nevertheless, policy makers and actors involved with the technology face difficulties in extracting practical guidelines for policy and business development since there are still many open questions beyond the technical aspects of engineering, and plant and fish production (Van Woensel and Archer, 2015). Those guidelines are especially desirable in the light of the precautionary principle (EEA, 2013) and the responsible research and innovation principles of the European Commission (EU, 2012). For new and emerging technologies, policy formulation principles can only be applied on the basis of information and, according to Leach et al. (2012) that information should help formulate direction, diversity and distribution for technology development pathways. However, sustainable technology development is characterized by uncertainties, high risks, huge investments and late returns on investments (Alkemade et al., 2007). Agricultural innovation needs to take an interdisciplinary perspective to capture the "multi-dimensional and multi-level interplay" (Joffre et al., 2017:129). The technological innovation systems (TIS) framework has been developed “... for understanding the complex nature of the emergence and growth of new industries and a focus on analyzing obstacles to this process" (Bergek et al., 2015: 52). Knowledge about emerging technological innovation systems can be obtained by analyzing their functions (Bergek et al., 2008; Hekkert et al., 2007; Alkemade et al., 2007), i.e., those activities that will contribute to achieve the aims of an innovation system. In its early phases, the aims of an innovation system are not "fixed", but rather arise from the expectations actors assign to the potential (not actual) technological performance (Alkemade and Suurs, 2012). We are currently lacking an overall conceptual and empirical understanding of aquaponics as a potentially emerging technological innovation system and its expectations and empirical insights into functional activities.

In this paper, we adapt the technological innovation system framework for an explorative interdisciplinary empirical analysis of the current developments of aquaponics. We understand aquaponics as a potential technology contributing to the development of more sustainable food systems. The aim of this paper is to conceptualise and empirically describe the current state of its development and, based on that, describe the functioning of the TIS that may explain current opportunities and obstacles for its development. We focus our analysis on the EU, using Germany as a case study, but also consider worldwide developments. The interdisciplinary perspectives of the authors have helped to connect natural sciences, agricultural economics and governance, technological and sectoral knowledge within the TIS perspective, to provide a comprehensive description about current transition processes in food systems.

\footnotetext{
1 The oldest examples are probably "chinampas" of the Aztecs, artificial islands in shallow lakes planted with crop. In the canals between these, fish were raised (Boutvelluc, 2007)
}

First, we position our research as an explorative approach in the technological innovation systems literature (Bergek et al., 2008), relate it to the sustainability paradigm (Weber and Rohracher, 2012) and develop an operational research framework to capture the integrative aquaponics technology within the environment of fully developed technological innovation systems of greenhouse vegetable production and aquaculture. Our explorative approach allows to discuss current functions that can facilitate or hinder the further development of aquaponics as a technology potentially contributing to sustainable food systems.

\subsection{Historical background}

In general, the search for solutions contributing to sustainable food production and consumption pathways can be developed by (1) reducing meat consumption, (2) minimizing food waste and (3) changing production processes (van der Goot et al., 2016). Efficiently produced vegetables and fish (the main products of aquaponics production) can potentially contribute to improving production and consumption habits, although dietary habits also play a vital role (Thøgersen, 2017). In Europe, the world's leading fish import market, there are large differences in fish consumption among countries, with more fresh fish being consumed in Spain, UK, Italy and France. Salmon, cod, hake and mackerel are the most consumed fish species in the EU (EUMOFA, 2016). Food production systems are also very diverse, from local to global and cannot be directly compared to one another (Baritaux et al., 2016). As a consequence, there is no "one fits all" solution to change food production and consumption. Aquaponic systems are expected to contribute to sustainability issues in food systems in different settings - urban/rural, small scale/large scale, developed/developing countries (Junge et al., 2017), yet assessing their contribution to more sustainable food systems faces methodological and data availability challenges (König et al., 2016).

Sustainable food system development also needs to consider broader infrastructural aspects beyond technical and physiological matters of food production and consumption behavior. Currently, already more than $50 \%$ of the world population lives in cities. It is expected that this percentage will grow to approximately $60 \%$, with a yearly increase of $1.7 \%$ until 2030 (UN, 2012). Many of cities are expected to grow significantly, with 37 urban agglomerations expected to become Megacities by 2025. At the same time, some cities are shrinking. Both growing and shrinking cities put pressure on the operation and management of conventional centralized infrastructure systems for energy, water and organic waste management (Gleick, 2002). Strategies for decentralized infrastructures are considered appropriate to address these developments (Schuetze et al., 2008; Binz et al., 2010), and aquaponics could contribute to urban cycling systems in terms of water, energy and food (Million et al., 2014). However, green space provision and food systems are not primarily organized within urban planning procedures, but rather within global-local value chains and are the result of the interplay of multiple actors and policy domains. (Re-) integration of food production into the city is discussed as a necessary element to achieve a circular urban metabolism (Benis and Ferrão, 2017; Tedesco et al., 2017). While urban agriculture cannot supply all of cities' needs, there is an inherent environmental logic and resilience within recognized historic models of incorporating urban food production, such as Johann von Thünen (1826, cited in Van der Schans and Wiskerke, 2012) and Howard (1902).

Modern aquaponics began with Jim Rakocy, with the first peer reviewed paper being published in 1981 (Rakocy and Allison, 1981). Mark McMurtry (McMurtry et al., 1990), from NC State University is acknowledged as the originator of aquaponics in the mid-eighties to early nineties, which he named Integrated AquaVegeculture 
System, or IAVS (http://iavs.info/). Today's flood-and-drain systems, as favoured by backyard practitioners, are derived from this model. Tom and Paula Speraneo adapted the McMurtry-System and introduced the name "flood-and-drain system". However, they have been strongly criticised by the IAVS proponents. Their website http://www.townsqr.com/snsaqua is out of service. James Rakocy designed the most widely copied design at The University of Virgin Islands (UVI) (http://www.uvi.edu/research/agricultural-experime nt-station/aquaculture-home/aquaponic-systems/default.aspx). In Germany, Bernhard Rennert (Rennert and Drews, 1989) was involved in research on combined fish and plant production in the 1980 s at the IGZ (Leibniz Institute of Vegetable and Ornamental Crops) and later further developed the idea of indirectly linking fish and plant production via a one-way valve to the ASTAF prototype at the IGB (Leibniz Institute of Freshwater Ecology and Inland Fisheries) (Kloas et al., 2015). In the 1970s at the Technical University of Berlin, a project group developed a fish-tomato greenhouse together with architects and alternative building owner communities as rooftop greenhouses for grey water recycling in BerlinKreuzberg (Der Spiegel, 1984) with an updated version (Million et al., 2014).

Nevertheless, in Europe, aquaponics research really began in the early 2000s with a paper by Graber and Junge (2009), the first European peer reviewed journal article. However, the number of scientific publications is still significantly lower than in fields of aquaculture, hydroponics or green rooftops (Junge et al., 2017). In this regard, and with only a few commercial facilities currently running in Europe (Villarroel et al., 2016), aquaponics can be termed as an emerging technology, a developing science topic and a potential innovation system to contribute to sustainable food systems.

\subsection{Conceptualizing aquaponics from an emerging technological innovation system perspective}

The combination of existing technological and biological components is, at first sight, a rather incremental innovation. Yet, given it is still in the early phases of development, as we have shown in our historical description, similar to other agricultural niches (Darnhofer, 2015; Knickel et al., 2017), it is still unclear how it will play role in a transition (Geels, 2004) towards more sustainable food systems and what impact this will have on the established ways of food production and consumption (regime level). Given the long-term nature of transitions, and the findings of rural development studies that processes between niches and regimes play a key role (Darnhofer, 2015), we chose the technological innovation system framework as a mid-grain conceptual starting point to gain insights into current innovation processes. The primary aim is to draw an explorative, but comprehensive picture about the current state as a basis required for further studies and methodological advances for agricultural innovation and transition scholars and practitioners.

Innovation research scholars have argued that innovation arises not only within the context of market failures and R\&D input and output indicators, but also as a result of a broader systemic background of the environment, preconditions and processes of innovation development (see e.g. Alkemade et al., 2007). Especially in agriculture there is a need for systemic views exceeding purely technology and market driven perspectives (Darnhofer, 2015; Joffre et al., 2017; Bokelmann et al., 2012). Innovation is "the process, whereby individuals or organizations bring existing or new products, processes and forms of organizations into social and economic use" (Rajalahti, 2012: 2). Typically, many actors, networks and institutions are involved in these research and development processes (Alkemade et al., 2007). Innovations result from the so- called functions an innovation system which provides for their development and diffusion (Bergek et al., 2008; Hekkert et al., 2007). Innovation system research assists the understanding of innovation processes in a systemic way.

To structure the analysis of the state of the art of aquaponics in Europe, we use the technological innovation systems (TIS) perspective as an analytical lens (Bergek et al., 2008) in order to describe the technological context and how actors, networks and institutions contribute to the development and diffusion of aquaponics. The TIS concept is a heuristic analytical construct (Bergek et al., 2008). It focuses on the analysis of socio-technical systems and on the development, diffusion and use of a particular technology (Bergek et al., 2008), where technology means the hardware, software and the technical knowledge embodied in both. Actors, networks and institutions are structural components of a TIS and the basis for further development, which is characterized by new actors, network expansion, and institutional coordination. Functions like knowledge development, legitimization, and resource mobilization, influence of direction, market formation, positive externalities and entrepreneurial experimentation mediate the links between the TIS elements and policies (Bergek et al., 2008; Hekkert et al., 2007; Alkemade et al., 2007).

The TIS analysis departs from the focal point of the technology rather than pre-setting system boundaries, i.e. sectorial or national innovation system approaches. As knowledge on aquaponics, and aquaponics facilities are geographically dispersed, we apply this approach with a special focus on the EU, but considering international developments. Due to the subsidiary principle of EU policy making, some institutional aspects differ for aquaponics across EU countries (Joly et al., 2015). We aim to illustrate how that can impact the national dynamics of technological development by providing a legal analysis and the results from interviews carried out in Germany from 2010 and 2016.

Two additional conceptual considerations ought to be taken into account because of the different research strands that need to be integrated in the perspective of aquaponics as a potentially emerging TIS for sustainable food production. First, the TIS approach can be useful to understand the development of aquaponics as a technology, although the conceptual links between innovation and transition research and sustainability are rather weak (Weber and Rohracher, 2012). More specifically, innovation system research has been criticized as not providing a sufficient basis for broader transformation oriented innovation policies (Weber and Rohracher, 2012), e.g. considering the existing technological regimes or sectorial socio-technical systems in which the new technology is embedded. In the case of aquaponics this implies that the existing production of fish and vegetables (aquaculture, marine and inland fisheries as well as hydroponics and land based vegetable production) need to be considered in terms of how they influence the development of the technology. Weber and Rohracher (2012) suggest that insights from transition research should be blended with innovation system research by analyzing functional failures, namely market, structural and transformational failures. This amendment is our first conceptual enlargement of the TIS approach.

Our second consideration derives from the conceptual challenge of multi-level aspects (Geels, 2004). While calls for more sustainable innovations often derive from a global perspective on sustainability issues (e.g. Rockström et al., 2009), Leach et al. (2012) call for finer grained considerations on innovation and sustainability, in order to consider what or who may benefit from the improved sustainability of an innovation. Considering different possible sustainability outcomes of individual aquaponic infrastructures, business models, rural/urban settings etc (König et al., 2016). but focusing on the analysis of the development path 
of aquaponics technology as a whole, we need a middle grain analytical level to analyze the current state of the development path. We therefore suggest to distinguish between different analytical levels of aquaponics to fully capture the technologies' integrated and complex nature and relate them to possible sustainability outcomes that may arise.

We subdivided aquaponics into three system levels in order to develop a comprehensive picture: (1) The System Core (the central hardware and technological processes) is the natural science and engineering base of all aquaponic systems and thus the point of origin for any analysis. Depending on how the system is set up, production process characteristics are determined together with the management of the system and the subsequent post-harvest activities, shaping sustainability indicators, e.g. water savings, nutrient recycling, production etc.; (2) The System Characteristics are all the factors that directly influence the processes and lead to the planning and setup of the System Core. They include factors such as the actors involved, their interaction through networks or business models, skills/knowledge base and stakeholders; (3) The Institutional System is the third level where factors from level 2 interact with social, economic, legislative and other institutional settings. For the institutional setting, we must acknowledge that legal, economic and political conditions are mainly constructed on a national level. Therefore, we use Germany as a case study to show how the institutional setting influences the development of the technology.

We conceptualize these three levels as interdependently emerging in the process of aquaponic development (potentially forming a TIS), delivering aquaponics as a technology and an innovative approach for sustainable food systems - or not. The claimed potential sustainability effects are illustrated on the right side of the graph, based on our search of the literature and empirical research about the expectations of the actors involved in the development process (called patterns of expectations by Alkemade and Suurs (2012) and as a portfolio of promises by Elzen et al., 2014). Fig. 1 illustrates our conceptual understanding of the System Core, System Characteristics and Institutional System in the light of the sustainability expectation associated with aquaponics.

Fig. 2 shows how aquaponics is developing at the interface between two developed technological innovation systems; greenhouse horticulture and recirculation aquaculture. Technological elements and actors of both knowledge domains are considered.

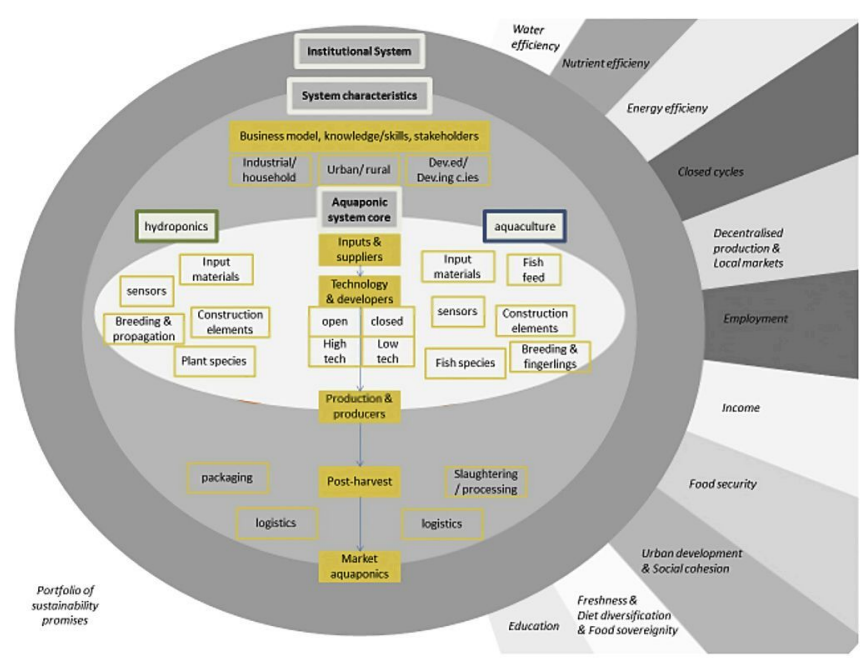

Fig. 1. Conceptualisation of aquaponics in the three system levels (1) System Core, (2) System Characteristics and (3) Institutional System and potential sustainability outcomes (on the right-hand side).

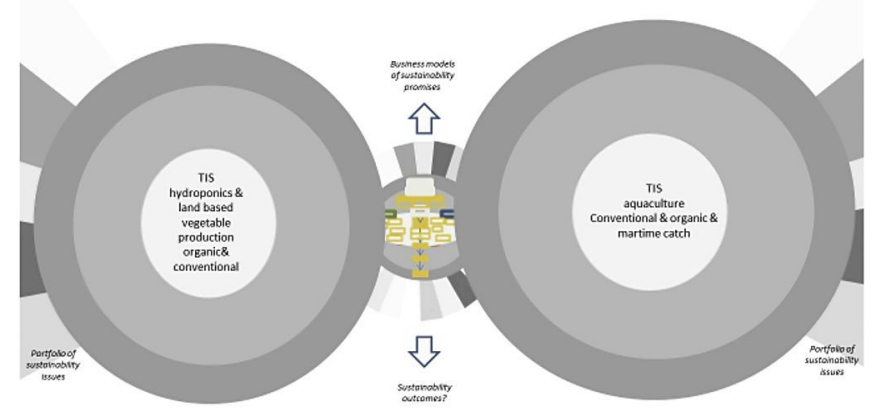

Fig. 2. Position of aquaponics as an emerging TIS at the interface between the developed TIS of vegetable production and aquaculture. (Portfolio of sustainability promises adapted from patterns of expectations by Alkemade and Suurs (2012) and as portfolio of promises by Elzen et al. (2014).

This constellation of emerging technological fields can also be found in other agricultural sectors, as analysed for example by Sutherland et al. (2015) between agriculture and the energy sector and between the agricultural and care sector (Hassink et al., 2012). Generally speaking, one may start from an aquaculture or a hydroponics/greenhouse vegetable production perspective to improve or overcome sustainability issues involved in the field or take an integrated view to develop the technology for a certain context, e.g. urban, developing countries. For any point of view, policies, markets and institutions of the dominant sectors are relevant to help identify their influence for the further development of aquaponics. Both developed technological innovation systems carry their specific sustainability issues (left and right side of the illustration).

\section{Materials and methods}

Our analysis is based on two field periods, each combining both an extensive literature review and empirical steps. The first exploratory phase with a regional and national sectorial focus included a desktop analysis of the regional technological innovation system of aquaculture, greenhouse horticulture and aquaponics, including the value chains for fish and tomato in 11 expert interviews. Documents included academic journal articles and reports on the general regional innovation system, the infrastructure for research and development in the field of environmental and agricultural sciences, market developments and consumer behavior. The interviews were transcribed and analyzed using content analysis with the software MaxQDA. The results were presented in one participatory scenario workshop and validated. Bottlenecks for further development were also identified for three scenarios with actors from fish and vegetable research and production, suppliers, research, extension and marketing in the BerlinBrandenburg area in 2010. The second analytical phase, setting the system boundaries of the TIS for the EU included different steps. First, a conceptual framework was developed to relate the technological innovation system and the sustainability perspective for aquaponics (Janker, 2016) and sustainability aspects of aquaponics were discussed (König et al., 2016). A survey of actors involved in the aquaponics in Europe was carried out by Villarroel et al. (2016). To analyze the institutional framework of the TIS, a governance analysis (including a comprehensive legal analysis) was conducted on all aspects that might affect use of the technology in different scenarios (construction of facilities, operation, marketing of the products and funding possibilities/subsidies) (Reinhardt, 2016). 
Results were then integrated, validated and extended based on 12 qualitative interviews with entrepreneurs, consultants and administrators to understand practical norms of the actors involved, the perceived importance of regulatory issues (law in action) and the self-organization and institutional representation of actors. Finally, expert exchange within the EU Aquaponics Hub, a networking action (Cooperation in Science and Technology, COSTFA1305, 2014-2018), contributed examples of legal and institutional practices, as well as uncertainties in EU member states regarding the setup of aquaponics facilities, thus contributing observations. The results of the individual steps of analysis were integrated through the presented conceptual framework by the interdisciplinary author team.

Our research followed an iterative character of data analysis and triangulation (Bergek et al., 2008). We present the results starting with a seemingly "technical" description of the technology, the structural components (actors, networks, knowledge base) and institutional aspects of the emerging TIS that reflects the interdisciplinary nature of the author team, thus assuring that the innovation system insights are connected to the state of the art of production and engineering aspects, as well as to innovation system scholars. Next, we considered the influence of existing TISs of aquaculture and greenhouse vegetable production. This allows us to interpret the results from a functional perspective. More specifically, we discuss how functional aspects arise from the expectation that aquaponics contributes to more sustainable food systems.

\section{Results}

\section{1. "Hardware"-the System Core}

The System Core (which refers to the main biological and technological processes) is the basis of all aquaponic systems and thus the point of origin in our TIS analysis. The System Core is first described by the principles and second by the elements and system goals that influence each other and lead to different types of settings for aquaponic facilities.

As for technological principles, aquaponic technology is based on the principles of the recycling of water and nutrients. Within the nitrogen cycle, hydroponically grown plants are fertilized with nitrogen from fish excretions, and simultaneously 'clean' the water for fish cultures by extracting the nutrients. A mutual benefit is created.

Regarding the elements of aquaponic systems and goals that should be achieved with the system, contradicting classifications can be found. Defining factors for the efficiency of the technology are the choice of plant-fish pairs, determining the necessary nutrients and water quality, including oxygen concentration and bacterial activity. In order to be as efficient as possible, the optimum ratio needs to be reached between fish-rearing and hydroponic components. Both coupled or closed, as well as decoupled or open systems are currently called aquaponics. Yet, open systems can be seen as just one method of plant fertigation, irrigation or integrated system. Closed systems are optimized in terms of resource use efficiency, while decoupled systems are designed for management feasibility and to avoid yield trade-offs on both the fish and plant sides of closed systems and reduce the risk of system fallouts (see also Goddek et al., 2016). Still today, finding appropriate fish-plant combinations without compromising yields is a key challenge (Suhl et al., 2016).

The System Core integrates the two food production technologies, hydroponics and aquaculture, as well as all processes related to the water and nutrient cycles. The technology can be implemented on varying scales (industrial - household), with varying system components and different system goals, influencing all other system levels but also connected systems, e.g. grey or rain water use in urban buildings or energy use from biogas plants (Maucieri et al., 2018). While some farms have developed a highly specialized production system, other farms experiment with different sources of energy and light or even involve organic plant substrates to achieve a zero-emission system. In order to be highly productive, farms adapt water and nutrient circles to plant or fish requirements. Automated feeding, watering and sludge removal tools can be used. The proximity of farms to urban areas can also influence aquaponic technology designs; due to the need to save space, high technology systems can be applied. Finally, a fair proportion of aquaponic farms are not concerned with being profitable, but serve as community projects or private gardens, thus applying self-made or ready to use hobby or low technology systems.

By combining the two production systems, aquaculture and hydroponics, the technology promises different positive sustainability effects: to reduce inputs, (e.g. water, mineral resources, pesticides, land) as well as to minimize pollution (e.g. wastewater) (Blidariu and Grozea, 2011) whilst maximizing production efficiency and stability, hence increasing revenues (Tyson et al., 2011). Food grown in the vicinity of the consumers will also reduce the dependency on transport of goods ("food miles", Paxton, 1994), energy and consumables. A diet rich in fish and vegetables will contribute to improved health (Rex and Blair, 2003). Plants provide ecosystem services for the city (enabling nutrient recycling, mitigating urban heat island effect, reduce storm-water runoff and food transport needs) and enhance living quality. Sustainable city farming can produce good quality food, thus contributing to public health. The further integration of the technology into building infrastructures promises to meet water and nutrient demand partly by source-separation of domestic greywater, treated on-site and reused for irrigation, and by rainwater harvesting. The promise of social sustainability depends more strongly on the specific system: some focus on solving food security issues (e.g. generating income, improving household food security), but others include labor aspects, such as ergonomic quality of the workspace. The provision of educational services (Hart et al., 2013) also has to be considered here. However, actual technology performance in terms of sustainability faces some methodological and data challenges, among them conceptual confusion about the social dimension (König et al., 2016). According to the literature, the social sustainability benefits of aquaponics include food safety and urban living quality (Veludo et al., 2012). As has been shown by Hart et al. (2013), aquaponics in the US has further contributed to social projects such as gardening for marginalized groups and environmental education.

\section{2. "Software"-factors shaping system characteristics}

Just as the System Cores differ significantly, so do the System Characteristics of aquaponic systems. System Characteristics are a result of how central actors, networks and institutions influence each other in the innovation process, according to Bergek et al. (2008). Important actors include innovators, business owners, and staff; customers and suppliers can be seen as actors but also as networks. Generally, especially in the early stages of technological innovation systems, central actors (founders, business owners, employees) closely interact with research institutions or expert networks. For new technologies such as aquaponics, knowledge production, distribution and diffusion play an important role and knowledge networks are essential (Suurs, 2009).

Business models in aquaponics not only involve choices about technological components, but also about products. In contrast to the main freshly consumed fish species in Europe (salmon, cod, 
hake and mackerel), today's aquaponics systems in Europe produce tilapia (27\%), catfish (10\%), ornamental fish (88\%), and trout (7\%) (Villarroel et al., 2016). Two interviewed experts indicated that tilapia, though suitable for closed aquaponic systems, is competing on the market with conventional produce from China and organic produce from Israel (consultant \#3, interview 2010, inland fish industry representative \#2, interview 2010). A diverse range of vegetable crops is grown in Europe's aquaponic facilities, with herbs (58\%, including basil), lettuce (47\%, including salad greens) and tomatoes $(32 \%)$ being the major crops. Tomatoes are the most important vegetable crop in the EU, more than half originating from Spain, Italy and Poland (Eurostat, 2016). However, it has to be considered that Europeans do not meet the recommendations for fruit and vegetable intake and depending on individual diets their intake of phytonutrients differ (Tennant et al., 2014).

\subsubsection{Actors and aquaponics facilities involved}

The field of aquaponics in Europe is still mainly shaped by actors from research, as found in the survey conducted by Villarroel et al. (2016). The 68 responding aquaponic actors in the survey were distributed among 21 European countries, 75\% involved in research activities and $30.8 \%$ in production. Only $11.8 \%$ of those surveyed had sold fish or plants in the past 12 months, indicating that commercial aquaponics production and marketing is still a minor activity among European actors and the technology is still in its infancy.

The aquaponics facilities of the responding actors were generally new (74.5\% constructed after 2010 ), and self-designed. Government grants funded $35.3 \%$ of the facilities. For $80.4 \%$ of respondents, aquaponics was not their main source of income. However, although actors from research are an important group in European aquaponics, the first commercial aquaponics facilities in Europe (Breen in Spain and BioAqua Farm in Bristol) have not benefitted from direct research collaboration, whereas others, e.g. UrbanFarmers, were initially linked to research. Aquaponics is also attractive to career changers that search for interaction with research in their kick-off phase (for technology development and transformation management) as well as building up their own internal knowledge management (e.g. documented at the websites of ECF, topfarmers).

Not surprisingly, with $42.6 \%$ of the participating organizations being universities, $19.1 \%$ commercial, $14.7 \%$ non-profit organizations and $8.8 \%$ vocational schools (14.7\% not specified), most respondents prioritized using aquaponics for educational purposes (Villarroel et al., 2016). Publicly funded research hence plays a major role for experimenting, whereas facilities financed by bank loans or investors do not play a role for facilitating the function of entrepreneurial experimenting and further development of aquaponic systems according to the survey. This is a second indication that aquaponics is still in an early phase of development in Europe.

The interviews we carried out in Germany with actors in both field phases (2010 and 2016) indicate that there are persistently different visions about the future of aquaponics with regard to its location (urban or rural), size (small scale versus industrial scale), marketing strategy (quantity versus quality, certification) and the role of consumers (direct marketing or marketing via supermarkets). Examples of these different visions are demonstrated by the following quotes:

"Closed aquaculture and aquaponic systems are not the solution for the future (in Germany) due to competition from certified fish catch and international closed aquaculture supply. It will remain a niche." (National fish industry representative Germany \#4, interview 2010)

"To be considered for organic certification, stocking rates need to be diminished. This would require high quality, specialty fish, not tilapia, for generating sufficient income." (consultant \#2, interview 2010)

"Such a facility needs to be ethically and economically reasonable at first hand. Certificates do not make the world a better place, they are an industry increasing the price of the product, irritating the consumer." (regional inland fish industry representative \#2, interview 2010)

"I am an urban farmer. I am not a farmer. We do not do organic production, which is sustainable agriculture. We do something else." (entrepreneur \#1, interview 2015)

"We will have to wait a while for this technology to be applied on an industrial scale ... Tilapia is a fish for the future." (aquaculture consultant \#5, interview 2015)

In sum, the markets and consumption patterns in the different EU countries require entrepreneurs to develop their own business model. This development is not guided by a consistent vision for the application of the technology in the aquaculture and horticultural sectors. One example is the different implementation of the plant part in soil (e.g. terra preta substrate) or soil-less substrates.

\subsubsection{Networks: interaction and intermediaries}

Interaction among aquaponic experts takes place both within the research networks of horticulture and aquaculture. Mostly, experts either have a background in one of the two fields, lacking the other knowledge domain. The EU COST network FA1305 is, to our knowledge, a hub that apart from the classical networks, brings experts from science, extension, experimental stations and entrepreneurs together to support interaction. Among the members, a network was created to represent commercial aquaponic actors (Association of Commercial Aquaponics Companies, ACAC). Apart from this, however, the specialized domains have little interaction and hence lobby work for the technology is difficult. Thus, explaining the barriers for the development of the technology to policy makers remains fragmented, as our interviews and participatory observation have shown. National associations of entrepreneurs are being created e.g., in southern France and in Germany.

The intermediaries involved are science and technology transfer agents, which can either be associated with universities or research institutes or have an entrepreneurial character, such as consultants. Yet, although intermediaries exist, the processes of interaction are not linear. That could be partly due to different hype cycles (Alkemade and Suurs, 2012), that can be initiated by media, funding programs or food trends and discourses, which the entrepreneurs adhere to (e.g. healthy food, transparent production in town). Also, the Google and Google Scholar analysis by Junge et al. (2017) shows that aquaponics gets a lot of attention in the social media in contrast to science, despite its early stage of development. Interaction through entrepreneurial expectation and business models is also important. "At the moment, all aquaponic firms are plant manufacturers, but they do not want to operate the farm themselves. Hence, they are all only starting at the very beginning." (entrepreneur \#1, interview 2015)

\subsubsection{Knowledge base and human capital}

Knowledge plays a vital role for the successful implementation of aquaponic systems. Most respondents in the survey of Villarroel et al. (2016) had a post-graduate degree (91.7\%), indicating that aquaponics is a knowledge intensive activity. Both knowledge from horticulture and aquaculture and the functioning and management of the technical devices play a role, but only recently have universities started teaching aquaponics. Educational programs would 
require explicit knowledge on plant and fish requirements, as well as technology and markets, with implicit knowledge on long term running, situation specific markets and regulatory knowledge. Missing knowledge may limit the quality of decisions taken for planning and running aquaponic systems. Some entrepreneurs try to bridge technological knowledge gaps in their business models by acting as a prime contractor, focusing on marketing and external knowledge acquisition through collaboration with research or consultants. Also, their knowledge obtained through own learning can be offered to other firms (Christ, 2016).

The survey of Villarroel et al. (2016) gives insights into knowledge diffusion. Regarding where the practitioners looked for information, most said they asked other growers $(n=31$ respondents), looked for information online (32), in print (30), at workshops (26) and via universities (33), but very few depended on government or federal agencies ( $\mathrm{n}=4$ respondents). Regarding personal knowledge of aquaponic facilities, most respondents said they agreed or strongly agreed that they knew how to modify their system pH (94\%), deal with fish diseases (64\%), control plant nutrition (62\%), fix plumbing issues (80\%), measure fish growth (86\%), eliminate plant pests $(40 \%)$ and understood regulations for processing and selling fish (58\%).

Knowledge on the challenges of long-term economic and ecologically viable closed aquaculture systems has a negative influence on the perception of the economic and ecological viability of aquaponics (regional inland fish industry representative \#2, interview 2010, national fish industry representative Germany \#4, Interview, 2010). „Politically, we do not want large scale aquaculture or aquaponic facilities, because they are not economically viable in the long term. You may know that there is none that is competitive. Mostly, they only resist as pilot projects for some years, as long as operating costs are financed via research institutes." (ministry official \#6, interview 2015)

Many questions are still open. Being able to identify them and to answer them requires both research as well as practical experimenting and knowledge integration and diffusion of both knowledge types (see Junge et al., 2017).

Several blogs and web practitioner networks (initially meant for DIY domestic practitioners) share information and also offer handson courses. In France, on the commercial aquaponics level, one public program (APIVA) actively disseminates information through their web site and via bi-annual sessions where entrepreneurs are invited.

\subsection{Institutions: institutional system}

The technological systems core, as well as its possible applications/business models, interacts with legal, political, economic, social and other Institutions, which have to be considered in order to analyze the functional dynamics of the TIS. Our analysis starts from the existing legal framework in the EU and Germany and extends to political, economic and social aspects as far as they could be revealed through qualitative stakeholder interviews and existing literature. No data has been collected yet on consumer preferences and demand potential, but a survey is under preparation within COST FA 1305. This would be informative to fully estimate potential developmental pathways for the TIS.

\subsubsection{Existing legal framework for aquaponics operations}

In a first step, we analyzed the legal framework for the construction and operation of aquaponic farms, the commercialization of products and the acquisition of agricultural subsidies from the EU, with a focus on Germany.

Regulations on construction exist on national, subnational and municipal levels. The analysis showed that there are no outright legal barriers for the construction of aquaponic farms in all envisioned scenarios (urban or rural, small and large). As recirculatory systems, installations do not require permission for surface water use, which is a major obstacle for other types of aquaculture. However, many open questions remain since the technology and its use are quite unorthodox. Also, political interests might hamper regulatory issues either at the state or regional levels. Major uncertainty arises from the question about whether aquaculture and hydroponics legally qualify as agriculture, which is relevant for planning, tax, and labor laws. If aquaponics is considered agriculture, construction is not possible in many urban areas. If it is not considered agriculture, construction faces difficulties in rural zones (Joly et al., 2015). Relevant case law is very limited.

The operation of an aquaponics system has to comply with regulations for fish and vegetable production. The aquaculture component especially touches many regulatory areas (e.g. hygiene, disease control, sludge removal, slaughtering, animal welfare). A number of individual permits are required. There is no unified permission procedure, as for other industrial animal farms, so that all legal aspects have to be negotiated with local authorities, therefore many individual permits are required.

"...., we are overregulated, maybe this is the core problem.... it is too difficult to get an overview." (aquaculture consultant '5, interview 2015)

"There is no legislative problem, only from case to case a problem of law interpretation by local authorities. ... The legislation is not different, but more or less detailed." (entrepreneur \#1, interview 2015)

Some open questions are not bound to aquaponics only, such as acceptable slaughtering practices for some kinds of tropical fish, or new types of fish feed such as insect meal to improve input sustainability. However, the main challenge for individual entrepreneurs in general remains the integration of knowledge and implementation within a viable business model, including an adapted marketing strategy. Few plant-fish combinations have been tested and a limited range of fish are suitable for closed systems, which will also limit market strategies.

The analysis revealed two antagonistic regulatory trends for the commercialization of products in Germany: on one hand, a number of legal exemptions facilitate direct sales of small-to medium sized agricultural producers. Whilst those exemptions are intended to benefit traditional small producers in rural areas, they might also be invoked to facilitate urban agriculture, such as aquaponics. On the other hand, neither the products of recirculatory aquaculture systems, nor vegetables grown in hydroculture qualify for "organic" labelling under the existing EU regulation. While some of the interviewed actors perceive this as a barrier for the technology development, others do not. Also, we do not yet know enough to qualitatively describe the relevant market niche of aquaponics.

Aquaponic farms have not received direct agricultural subsidies in Germany. EU fishery funds are distributed by the federal states, which usually favor maritime or traditional fresh water aquaculture (carps and trout). Some German federal states recently appear to open up towards more innovative types of aquaculture. Most funding so far appears to have come through research financing. Feed-in-tariffs under the old German renewable energy law have become an indirect source of subsidies for aquaculture, with reduced incentives under the new renewable energy law: recirculatory systems are developed in connection with biogas plants, which are legally required to make use of heat and use animal waste as substrate (ministry official \#6, interview 2015). Aquaponic projects may also qualify for public funding for urban development 
or social projects.

\subsubsection{Future development}

In a second step of analysis, the findings about individual regulations were aggregated to see how much aquaponics aligns with more general political and regulatory values. In summary, aquaponics whilst being in line with the stated objectives of nearly all affected regulatory areas, is quite unorthodox and often does not align with the underlying paradigms of current regulation. Planning laws in Germany as well as Switzerland and France do not consider urban or indoor agriculture. The EU and national organic labeling regulations are geared to sustainability, but focus on the holistic concept around soil based food production. Thus, nontraditional, high-tech aquaculture is not generally promoted on a political level in Germany. A national aquaculture strategy, which recognizes innovative, high-tech aquaculture systems has only recently been formulated at the German national level.

The experience of authorities and entrepreneurs with regulations is generally low and specific circumstances cannot easily be transferred. As a result, norms regarding aquaponics have not been established yet. As many relevant questions are regulated on a subnational level, diffusion of regulatory knowledge is limited. Many questions have to be considered open for the moment: whilst legal uncertainty may open up possibilities for creative entrepreneurs in individual cases, uncertainty generally inhibits investment. As food production is governed by the precautionary principle, open questions in the law do not necessarily translate into opportunities for entrepreneurs.

"The point is that the aquaponics industry does not exist yet and lacks internal standards, such as for example clean handling practices. These are soft criteria, they are not written down anywhere in the law." (entrepreneur \#1, interview 2015)

Changing the institutional framework - i.e. changing individual regulatory barriers, promoting new values and establishing certain norms, would require self-organization of the sector and political representation. At the moment however, no relevant body has been established. Although efforts have been made by individual actors, no stakeholder has so far proved strong enough to integrate the interests of all the others. Presently, only the COST Action FA1305 interlinks actors from science and business at the European level. The ACAC, which began in 2015, is an off-shoot of that action. Interests in the neighboring fields also appear to be too fragmented to foster cooperation. In aquaculture, marine production is better organized than traditional inland aquaculture (carp and trout), which has developed over centuries and is geared towards the interests of small, family run businesses in rural areas. Large scale vegetable growers might eventually show an interest in adopting multi-circle technology, if it fulfills its productivity promises. However, so far, they have showed little interest in the high-priced urban farming sector.

\subsubsection{Role of intellectual property rights}

Intellectual property rights (IPR), especially patents, can play a key role in the development of TIS. Solid IP protection is often seen as essential for start-up-businesses to raise capital. Patents are also important parameters for the distribution of public funds. The importance IPR holds for the development of aquaponics depends on the vision of the future. If seen as a form of high-tech, controlled environment agriculture, aquaponics promises technological advances on several levels, relating to systems architecture, technical features or even genetics. If seen primarily as a social innovation that consists in a community-based, socially and environmentally "sustainable" alternative to industrial food production, patents might not play a big role. The concept of aquaponics itself cannot be patented.

Google Patents currently shows around 340 patents related to aquaponics, with around 200 from China and 100 from the US. However, the interviewed practitioners seemed to attach little significance to IPR, emphasizing the need for market development and the importance of professional skills in food marketing. Patents therefore do not seem to be a key success factor, because the technology risks are more related to the integration of highly specific knowledge, and long term complex system management capabilities. This finding is in line with Bokelmann et al. (2012), who found that patents are not key success factors for agricultural innovation processes in Germany. Yet, the protection of ideas, as possible in France (Soleau letter) or Belgium (i-depot), might help to maintain the rights of using an entrepreneur's idea, even if this idea has later been registered as a patent by someone else.

Examples from the US and around the world show aquaponics is mostly promoted by amateur, "garage"-type inventors, who seem to rely heavily on the free exchange of knowledge. As a technological and social innovation, aquaponics may thus overcome traditional innovation paradigms also in the field of IPR.

To sum up the institutional aspects, two experts shall be quoted, to prove our conceptual consideration of the national, even regional level as relevant for implementation of aquaponics: "But nowhere is there an article where I can read what solutions there are for the different legal aspects .... But what for? In the end there is a different procedure in each region" (entrepreneur \#1, interview 2015) "The political economy differs from country to country" (aquaculture consultant '5, interview 2015)

\subsection{Influence of existing technological regimes of aquaculture and hydroponics}

Dietary recommendations regarding fish and vegetable consumption may play a favorable role in increasing the demand for aquaponic products, which are seen as healthy and sustainable. Yet, consumption of fish is influenced by regional and cultural effects that need to be addressed to change eating behaviors (York and Gossard, 2004). Whilst wild fish products have decreased worldwide over the past 40 years, it still continues to play a major role through imports to the EU and other developed countries. Aquaculture, starting from its infancy in the 1970 s (Parker, 1979), has so far prevented a downturn in global fish supplies. While it makes up $24 \%$ of the European fish consumption (EUMOFA, 2016), on a global level, aquaculture accounts for almost half of the fish consumed (FAO, 2014), being the fastest growing food production sector. However, while EU countries continue to aspire to consume more fish than they produce, demand is not always balanced by sustainable production methods (Thurstan and Roberts, 2014; Joffre et al., 2014). Given the methodological challenges in assessing sustainability issues in aquaculture (Samuel-Fitwi et al., 2012; Ottinger et al., 2016), at this early stage of development there are no explicit regional indications that decouple environmental issues in aquaculture and EU fish consumption through aquaponics production.

It is not clear yet whether consumers will accept fish produced in aquaponics and how their perception of the quality of the aquaponic products will affect economic viability. As with early developments of aquaculture, we can expect that, if and when certain quality criteria are met, price will play a role in influencing consumer decisions (Parker, 1979). In contrast to consumer perspectives, Villarroel et al. (2016) did not find that producers were strongly motivated to produce their own fresh food, but were more focused on technological feasibility. Research on consumer acceptance and marketing will help to a better understanding of the 
potential of the technology, especially regarding the sustainability effect of a "real" substitution (Parker, 1979), where aquaponic fish replace other sources with a more negative environmental impact (e.g. meat, wild catch, fish from unsustainable aquaculture). However, this needs to be better understood and differentiated on the European market since aquaponics products will also "compete" with MSC, ASC or organic labels that have expanded in the last 10 years (FAO, 2014).

On the vegetable side, health recommendations for the daily intake of fruit and vegetable consumption have not been met in developed countries, making communication and marketing necessary (Rekhy and McConchie, 2014). Consumer health and "green" attitudes have been studied, but repeatedly reveal a gap between motivation and actual buying and consumption, suggesting that business strategies and food policies play a prominent role (Sillani and Nassivera, 2015). On the production side there are also regional differences and trade flows within Europe for fresh vegetables (EP, 2011; Eurostat, 2016), apart from consumption differences. Currently the most influential markets for the development of aquaponics are tomato, salad and herbs, the major crops in existing aquaponics installations. Tomatoes are the major greenhouse vegetable crop and it has undergone a period of product differentiation in the last 15 years, with forms and taste variations becoming important product characteristics, beside price. A similar trend towards product differentiation can be seen for lettuce and fresh cut herbs in the last 10 years. In the last 30 years, supermarkets have become the main marketing channel for vegetables in Europe, resulting in high price competition between growing regions and limiting current investment capabilities of many greenhouse growers (EP, 2011; Wellner et al., 2017; BMEL, 2017). Due to this price competition, interviewed actors perceive only the direct marketing strategies as economically feasible.

The literature on aquaponics suggests that production standards and prices of greenhouse vegetables are the leading considerations to meet economic targets at current market conditions (Kloas et al., 2015; Suhl et al., 2016). However, interviewees stated that the economic conditions in the conventional greenhouse sector are not the right point of reference for aquaponics, if it is to play a role in urban food systems.

"Producing tomato at 38 cents per kilogram and having to sell them for 35 is not an attractive business, but it has been the reality for tomato growers for generations. How should we communicate the different marketing approach for aquaponics?" (entrepreneur \#1, Interview, 2015)

To sum up, specialized value chains have developed in both fish and vegetable markets and as a result, there are no logistical links in the value chains between fish and vegetables, since they are handled separately in two product categories. Prices from the aquaculture and vegetable sectors influence the design of business models of aquaponics towards direct marketing. Thus, aquaponic businesses will favor direct marketing to consumers or restaurants, but also include demonstration and educational services for extra income. Promotion from a neighboring sectorial environment may come from biogas or urban water infrastructures (green-blue building block for urban development), yet financing these capitalintensive facilities is an issue: "There is a trend of biogas operators to favor large facilities. Yet they cannot find investors." (ministry official \#6, interview 2015)

After having described the results of our exploratory empirical research, we discuss them in the next section from a functional perspective in order to arrive at an evaluative description of the state of development of aquaponics as a TIS.

\section{Discussion of functional aspects}

\subsection{Knowledge diffusion}

Knowledge, and especially integration is key to aquaponics. If aquaponics is to contribute to solving sustainability issues (e.g. by integrating plant production in the aquaculture branch), the diffusion of knowledge and openness for new capacity building in the established TIS will be crucial. If not, weak network failure may lead to capability failure (Weber and Rohracher, 2012) in that aquaponics is not contributing to the transformation of the existing socio-technical systems of aquaculture and greenhouse horticulture. Many questions regarding operating and selling products (especially hygiene, disease control and feed) are harmonized under EU-Law. However, the construction of facilities is always handled by national, regional and municipal authorities and therefore may differ considerably. We do not have empirical insights regarding how knowledge is spread among local authorities on approval procedures, but based on participatory observation we did notice knowledge exchange on these issues across Europe within the COST network.

Aquaponics itself is seen as a suitable facility to educate and to diffuse knowledge, e.g. about nutrition cycles or the technology itself. However, also in educational settings knowledge for long term management $(\mathrm{pH}$ control) and system viability remains a challenge (Hart et al., 2013; Villarroel et al., 2016). Yet, the social effects on the students do not seem to have been considered in peer reviewed journals yet. Also, in the light of societal discourses about sustainability, ethical and transparency issues in the food sector in Europe, there is no empirical evidence about consumer knowledge of aquaculture, hydroponics and aquaponics, on which communication and marketing strategies could build upon.

As there are still many open questions related to the technology, knowledge infrastructure is critical (Weber and Rohracher, 2012), because the return on investment is limited in a market where the products compete with horticultural and aquaculture products.

\subsection{Legitimation}

Aquaponic products are a substitute for "normal" or conventional food products and organically produced fish and plants on the market. Hence, prices will be compared and the final price will need to be justified by telling the story and quality behind the products. It remains to be seen in the long run if pioneer margins on products can finance further development or whether the system design has to accomplish similar productivity (e.g. Kloas et al., 2015). Improvements in sustainability through the use of the technology are not yet clear among those already involved in aquaponics, as the survey of Villarroel et al. (2016) shows. Different visions for the technology reported in the literature and in our interviews might bear the risk of a directionality failure to establish coordination between actors to arrange a corridor of acceptable development paths (Weber and Rohracher, 2012). At the moment, there is little if any knowledge about the technological demand of horticultural and aquaculture producers and the acceptance of consumers and therefore little information to legitimize further paths of development (demand articulation failure, according to Weber and Rohracher, 2012).

\subsection{Resource mobilisation}

There are different experiences in developed countries about how to handle intellectual property rights strategies. As aquaponic systems are each specific to the local conditions and target consumers, it is knowledge intensive, which is the most critical success 
factor besides the financial capital involved, depending on the system design and size. However, there is still a lot of insecurity involved in setting up the systems, and even more in their long term economic management and system stability, due to its complexity. Regulatory uncertainty poses an additional problem, which leads to institutional failure and policy coordination difficulties across levels and policy fields (Weber and Rohracher, 2012).

It remains to be seen how supermarkets and value chain actors will incorporate aquaponics produce, what coordination issues arise and how holistic the technology could then be in fulfilling its sustainability promises.

\subsection{Influence on direction of research}

The interviews and the quantitative survey of Villarroel et al. (2016) showed that the visions, motivations and expectations about the future of aquaponics differ. Within this diversity the development of urban farms in signature locations of "rich" cities (with little green spaces) may be one promising path for aquaponics, requiring innovative marketing practices. On the other hand, proponents of multi-systems for large installations argue that in the future any greenhouse should have a fish tank attached to it, or vice versa. It is not easy to see which of the existing combinations of the technology will form the future path and what role they will play in relation to conventional aquaculture and vegetable production. Also, there are several sustainability problems which aquaponics could address, but which may be impossible to deliver in one system setup. Therefore, future pathways will always need to involve a diversity of approaches. It is also important to note that high tech systems will not be economically viable in developing or emerging countries markets: "We have a high tech facility, involving high production costs. If you look e.g. to Brazil: Which markets would pay for the produce?" (entrepreneur \#1, interview 2015) The strength of the technology is hence its adaptability. For this, knowledge and capacity building are critical factors as well as the ability to link the different discursive spheres of value chain actors (horticulture and aquaculture) to involve enough actors to formulate a joint vision for different applications and coordination of development activities. For the time being, there is little lobby within the field of agriculture and aquaculture for aquaponics that would allow to develop policies allowing for experimentation and keeping the corridor of potential applications open and to deal with the uncertainty this implies. A branch marketing for aquaponics could help to discuss practical challenges for development.

As we have laid out in the current paper, the sustainability outcomes of the technology can only be seen as potentials. We did not find a system of monitoring economic factors (e.g. FAO data) such that the actors within the emerging technological innovation system can perform what Weber and Rohracher (2012) call a selfreflexive governance in the direction of development paths.

\subsection{Market formation}

Aquaponics is a process innovation, not a product innovation the products are competing on the market with conventionally or organically grown produce from horticulture as well as with conventional salt water and fresh water products, responsible or organic aquaculture and wild catch. Due to the soilless cultivation and density of fish stocking, aquaponics cannot be certified as organic, as the rationales of both production systems differ. For the time being, there is only evidence that marketing responsible or sustainable food produce is a challenge, because it is often associated with higher consumer prices. The challenge for closed systems is communication, in order to generate income and desired positive externalities. Policies to prevent negative externalities of food production may therefore play a role in promoting favorable external conditions (market failure, see Weber and Rohracher, 2012).

\subsection{Positive externalities}

As has been discussed by König et al. (2016), aquaponics can potentially deliver positive externalities with regard to sustainability, depending on the setup of the system. However, as there are no standards or norms yet, there is no differentiation between systems, but marketing generally works with the potentials of the technology, not with the sustainability contribution of a specific system. To achieve the full potential of the System Core, the exploration of possibilities but also clarifying risks of integrating aquaponics in urban water cycles and replacing of fish meal feeding through insect protein also needs to be considered. However, this increases the complexity and institutional bottlenecks even more. Handling the complexity within the design and planning process but also in the development of a supporting environment of a technological innovation system is a challenge. The delivery of other positive externalities such as green urban development or nutrition education depend, not on the technical, but on the business model. Yet, social norms or orders of justification (Boltanski and Thévenot, 2007) overcoming the dichotomy between sustainability as "natural" and high tech food production as "industrial" have to evolve both in the discourses in the sectors as well as for consumers and could be supported by a reflexive sustainability assessment/monitoring.

\subsection{Entrepreneurial experimentation}

Future pathways of technologies can be explored by research and development, but also require entrepreneurial experiments. As food markets are price sensitive, risk taking innovations cannot be taken by many existing enterprises, especially if the risk of the investment is perceived as high due to technological and marketing knowledge gaps. Large scale commercial projects face high marketing risks, high technological and management complexity and a still uncertain regulatory situation. For experimentation, at the moment we see advantages for smaller systems which show reduced complexity and qualify for several legal exemptions. Indeed, the small-scale sector shows optimism and a surprising degree of self-organization over the internet. There might be room for creating additional social innovations, such as participatory science or a rise of "Prosumers" (producers and consumers), as in the renewable energy sector. It remains interesting to observe and understand what impulses for further pathways emerge from the small scale and hobby field and what sustainability externalities they will develop.

\section{Conclusions}

We explored aquaponics as an emerging TIS, conducting both document and empirical research. We identify challenges regarding functional aspects that derive from its complexity, its institutional environment as well as from the sustainability paradigm. This results in a risky environment for entrepreneurs and investors, forcing the setup of facilities in the EU that do focus on production, but also on marketing and market formation. While information on sustainability outcomes is missing for a reflexive development process, entrepreneurs should be clear about their claims regarding sustainability in order not to risk legitimation. Situation specific sustainability goals could be achieved with a facility, forming the basis for system design and a clear marketing strategy.

According to the classification of phases of TIS development, we 
conclude that aquaponics is in the formation phase. Bergek et al. (2008) indicate that this phase may exceed 10 years. Such a period is characterized by high entrepreneurial insecurity in terms of technology and potential markets, little economic activity and lack of self-enforcing positive feedback loops or positive externalities. Nor are there meaningful prices or a clear demand. According to Bergek et al. (2008) and supported by our results, for aquaponics to become one more piece in the puzzle of sustainable food systems, actors are encouraged to identify the best application fields of the technology. Therefore, (barriers to) knowledge sharing, entrepreneurial experimentation and building of legitimation towards potential customers are all important, among the existing TIS actors in horticulture and aquaculture and within the institutional environment.

We would like to finish our discussion of future potential developments of aquaponics by suggesting that focusing on marketing the technology to consumers might be questioned as the direction of development efforts. Rather, we suggest to consider the potential sustainability impact of a stronger orientation about "How aquaponics can contribute to solve sustainability issues in aquaculture and horticulture?", and what sustainability experimentation setting would be needed to enable science, business, policy and consumers to answer this question without repeating the development path of both existing TIS. According to our findings and in line with the considerations on sustainability experimentation by Sengers et al. (2016), aquaponics could become an interesting case for overcoming the divide between outsider sustainability experiments and regime lock-in by broadening the currently involved perspectives.

\section{Author contributions}

The paper was initiated within the framework of the COST Action FA1305, building on a prior internal working paper. B.K. wrote the first version, provided by inputs from J.J., T.R., M.V. and R.J. All authors provided valuable inputs and participated in discussions. All authors read and approved the final manuscript.

\section{Conflicts of interest}

The authors declare no conflict of interest.

\section{Acknowledgments}

This research received funding from the German initiative "business meets science" by The Federal Ministry of the Interior and within the framework of the COST Action FA1305. The authors would like to thank Christoph van Ballegoy, Katharina Diehl, Sven Lundie, Anett Kuntosch, Wolfgang Bokelmann and Werner Kloas as well as colleagues from COST Action FA1305 for productive discussions and input.

\section{References}

Alkemade, F., Suurs, R.A.A., 2012. Patterns of expectations for emerging sustainable technologies. Technol. Forecast. Soc. Change 79 (3), 448-456.

Alkemade, F., Kleinschmidt, C., Hekkert, M., 2007. Analyzing emerging innovation systems: a funktions approach to foresight. Int. J. Foresight Innovat. Policy 3 (2), $139-168$.

Ashley, J.M., 2016. Food Security in the Developing World. Academic Press. Elsevier, London.

Baritaux, V., Houdart, M., Boutonnet, J.-P., Chazoule, C., Corniaux, C., Fleury, P., et al., 2016. Ecological embeddedness in animal food systems (re-)localisation. A comparative analysis of initiatives in France, Morocco and Senegal. J. Rural Stud. 43, 13-26.

Benis, K., Ferrão, P., 2017. Potential mitigation of the environmental impacts of food systems through urban and peri-urban agriculture (UPA) - a life cycle assessment approach. J. Clean. Prod. 140 (S), 784-795. https://doi.org/10.1016/ j.jclepro.2016.05.176.

Bergek, A., Jacobsson, S., Carlsson, B., Lindmark, S., Rickne, A., 2008. Analyzing the functional dynamics of technological innovation systems. Scheme Anal. Res. Policy 37 (3), 407-429.

Binz, C., Larsen, T.A., Maurer, M., Truffer, B., Gebauer, H., 2010. Zukunft der dezentralen Wassertechnologien. EAWAG, Dübendorf, Switzerland, p. 59.

Blidariu, F., Grozea, A., 2011. Increasing the economical efficiency and sustainability of indoor fish farming by means of aquaponics - review. Animal Sci. Biotechnol. $44(2), 1-8$.

BMEL, 2017. Ertragslage Garten- und Weinbau. Daten Analysen. Available at: https://www.bmel-statistik.de//fileadmin/user_upload/monatsberichte/GBB2000000-2017.pdf. (Accessed 25 September 2017).

Bokelmann, W., Doernberg, A., Schwerdtner, W., Kuntosch, A., Busse, M., König, B. Siebert, R., Koschatzky, K., Stahlecker, T., 2012. Sektorstudie Zur Untersuchung des Innovationssystems der Deutschen Landwirtschaft. https://doi.org/ $10.18452 / 13522$.

Boltanski, 1., Thévenot, L., 2007. Über die Rechtfertigung. Eine Soziologie der kritischen Urteilskraft. Hambg. Edition.

Boutvelluc, J., 2007. Aztecs' Aquaponics Revamped. Available online: http://napava lleyregister.com/lifestyles/home-and-garden/columnists/master-gardener/azte cs-aquaponics-revamped/article_b67bd13c-fd17-562f-a3a1-3862010ce144. html. (Accessed 30 September 2017).

Christ, P., 2016. Fisch meets Gemuise. An vielen Orten Deutschlands wird an der Technologie "Aquaponik" getüftelt. raum zeit 202, 44-47.

Damhofer, I., 2015. Socio-technical transitions in farming: key concepts. In: Sutherland, L.-A., Darnhofer, I., Wilson, G.A., Zagata, L. (Eds.), 2015. Transition Pathways towards Sustainability in European Agriculture. Case Studies from Europe, pp. 17-32.

EEA, 2013. Late Lessons from Early Warnings II. Summary-1. European Environmental Agency. EEA Report, No 1/2013.

Elzen, B., Janssen, A., Bos, B., 2014. Portfolio of promises. Designing and testing a new tool to stimulate transition towards sustainable agriculture. In: IST Conference Proceedings. Utrecht, pp. 27-29. August 2014.

EP, 2011. The EU Fruit and Vegetables Sector. Overview and Post 2013 CAP Perspective. Directorate General for Internal Policies. Policy Department B Structural and Cohesion Policies. Agriculture and Rural Development.

EU, 2012. Responsible Research and Innovation. Europe's Ability to Respond to Societal Challenges. European Union. https://doi.org/10.2777/11739.

EUMOFA, 2016. The EU fish market. 2016 Edition. In: European Market Observatory for Fisheries and Aquaculture Products. European Union, 10.2771/442971.

Eurostat, 2016. The Fruit and Vegetable Sector in the EU - a Statistical Overview. European Union. Available at: http://ec.europa.eu/eurostat/statistics-explaine d/index.php/The fruit and vegetable_sector_in the EU_-_a statistical_ove rview\#Output_values_and_prices. (Accessed 4 April 2017).

FAO, 2014. The State of World Fisheries and Aquaculture. Opportunities and Challenges. Food and Agriculture Organisation of the United Nations. 2014, Rome, p. 223.

Garnett, T., 2011. Where are the best opportunities for reducing greenhouse gas emissions in the food system (including the food chain)? Food Policy 36, 23-32.

Geels, F.W., 2004. From sectoral systems of innovation to socio-technical system$s-i n s i g h t s$ about dynamics and change from sociology and institutional theory. Res. Policy 33 (2004), 897-920.

Gleick, P.H., 2002. Water management: soft water paths. Nature 418 (6896), 373.

Goddek, A., Espinal, C.A., Delaide, B., Jijakli, M.H., Schmautz, Z., Wuertz, S., Keesman, K.J., 2016. Navigating towards decoupled aquaponic systems: a system dynamics design approach. Water (8), 303.

Graber, A., Junge, R., 2009. Aquaponic systems: nutrient recycling from fish wastewater by vegetable production. Desalination 246, 147-156.

Hart, E.R., Webb, J.E., Danylchuk, A.J., 2013. Implementation of aquaponics in education: an assessment of challenges and solutions. Sci. Educ. Int. 24 (4), 460-480.

Hassink, J., Grin, J., Hulsink, W., 2012. Multifunctional agriculture meets health care: applying the multi-level transition sciences perspective to care farming in The Netherlands. Sociol. Rural. 53 (2), 223-245.

Hekkert, M.P., Suurs, R.A.A., Negro, S.O., Kuhlmann, S., Smits, R.E.H.M., 2007. Functions of Innovation systems. A new approach for analysing technological change. Technol. Forecast. Soc. Change 74, 413-432.

Howard, E., 1902. 1898. Garden Cities of Tomorrow. London, S. Sonnenschein \& CO. Ltd (available online at Google Books).

Janker, J., 2016. Innovation Pathway of Aquaponics and Sustainability. Master Thesis. Humboldt-Universität zu Berlin, 02.2016.

Joffre, O.M., Klerkx, L., Dickson, M., Verdegem, M., 2017. How is innovation in aquaculture conceptualized and managed? A systematic literature review and reflection framework to inform analysis and action. Aquaculture 470 (2017), $129-148$.

Joly, A., Junge, R., Bardocz, T., 2015. Aquaponics business in Europe: some legal obstacles and solutions. Ecocycles 1 (2).

Junge, R., König, B., Villarroel, M., Komives, T., Jijakli, M.H., 2017. Strategic points in aquaponics. Water 9 (3), 182.

Kloas, W., Groß, R., Baganz, D., Graupner, J., Monsees, H., Schmidt, U., Staaks, G., Suhl, J., Tschirner, M., Wittstock, B., Wuertz, S., Zikova, A., Rennert, B., 2015. A new concept for aquaponic systems to improve sustainability, increase productivity, and reduce environmental impacts. Aquac. Environ. Interact. 7 (2), $179-192$.

Knickel, K., Redman, M., Darnhofer, I., Ashkenazy, A., Calvao Chebach, T., Sumane, S., 
Tisenkopfs, T., Zemeckis, R., Atkociuniene, V., Rivera, M., Strauss, M., Kristensen, A., Schiller, L.S.S., Koopmans, M.E., Rogge, E., 2017. Between aspirations and reality: making farming, food systems and rural areas more resilient, sustainable and equitable. J. Rural Stud. https://doi.org/10.1016/ j.jrurstud.2017.04.012. July 2017.

König, B., Junge, R., Bittsanszky, A., Villarroel, M., Komives, T., 2016. On the sustainability of aquaponics. Ecocycles 2 (1), 9-15.

Leach, M., Rockström, J., Raskin, P., Scoones, I., Stirling, A.C., Smith, A., Thompson, J., Millstone, E., Ely, A., Arond, E., Folke, C., Olsson, P., 2012. Transforming innovation for sustainability. Ecol. Soc. 17 (2), 11.

Love, D.C., Fry, J.P., Genello, L., Hill, E.S., Frederick, J.A., Li, X., Semmens, K., 2014. An international survey of aquaponics practitioners. PLoS One 2014 (9), e102662.

Maucieri, C., Forchino, A.A., Nicoletto, C., Junge, R., Pastrees, R., Sambo, P., Borin, M. 2018. Life cycle assessment of a micro aquaponics system for educational purposes built using recovered material. J. Clean. Prod. 172, 3119-3127.

Mclntyre, B.D., Herren, H.D., Wakhungu, J., Watson, R.T., 2009. International Assessment of Agricultural Knowledge, Science and Technology for Development (IAASTD). Synthesis Report. Available at: http://wedocs.unep.org/handle/ 20.500.11822/7862. (Accessed 30 September 2017).

McMurtry, M.R. Nelson, P.V., Sanders, D.C. Hodges, L, 1990. Sand culture of vegetables using recirculated aquacultural effluents. Appl. Agric. Res. 5 (4), $280-284$.

Million, A., Bürgow, G., Steglich, A., Raber, W., 2014. Roof water-farm. Participatory and multifunctional infrastructures for urban neighborhoods. In: Roggema, $\mathrm{R}$, Keffe, G. (Eds.), Proceedings. 6th AESOP Food Planning Conference. Leuuwarden, The Netherlands, 5-7 November 2014, 659-678.

Ottinger, M., Clauss, K., Kuenzer, C., 2016. Aquaculture. Relevance, distribution, impacts and spatial assessments - a review Ocean Coast. Manag. 119, 244-266.

Parker, R.G.B., 1979. Fish farming in Europe. Food Policy 4 (3), 194-202.

Paxton, A., 1994. The Food Miles Report: the Dangers of Long-distance Food Transport, vol. 1994. SAFE Alliance, London, UK. Available at. http://www.susta nweb.org/publications/?id=191. (Accessed 4 April 2017).

Pretty, J., Sutherland, W.J., Ashby, J., Aubuim, J., Baulcombe, D., Bell, M., Bentley, J. Bickersteth, S., Brown, K., Burke, J., Campbell, H., 2010. The top 100 questions of importance to the future of global agriculture. Int. J. Agric. Sustain. 8 (4), $219-236$.

Rajalahti, R., 2012. Sourcebook overview and user guide. In: Agricultural Innovation Systems. An Investment Source Book. World Bank, pp. 1-13. https://doi.org/ 10.1596/978-0-8213-8684-2.

Rakocy, J.E., Allison, R., 1981. Evaluation of a Closed Recirculating System for the Culture of tilapia and Aquatic Macrophytes. In: Allen, L.J., Kinney, E.C. (Eds.) Proc. Of the Bio-engineering Symposium for Fish Culture. Publ. No. 1, vol. 1981 American Fisheries Society, Bethesda, MD, pp. 296-307.

Reinhardt, T., 2016. Institutionelle Rahmenbedingungen des Technologischen Innovationssystems "Aquaponik". Master Thesis. Humboldt-Universität zu Berlin, 21.12.2016.

Rekhy, R., McConchie, R., 2014. Promoting consumption of fruit and vegetables for better health. Have campaigns delivered on the goals? Appetite 79 (S), 113-123.

Rennert, B., Drews, M., 1989. Eine Möglichkeit der kombinierten Fisch- und Gemüseproduktion in Gewächshäusern. Fortschr. Fisch. wiss 8, 19-27.

Rex, D., Blair, A., 2003. Unjust des(s)erts: food retailing and neighbourhood health in Sandwell. Int. J. Retail Distrib. Manag. 31 (9), 459-465.

Rockström, J., Steffen, W., Noone, K., Persson, A.., Chapin III, F.S., Lambin, E.F. Lenton, T.M., Scheffer, M., Folke, C., Schellnhuber, H.J., Nykvist, B., de Wit, C.A. Hughes, T., van der Leeuw, S., Rodhe, H., Sörlin, S., Snyder, P.K., Costanza, R. Svedin, U., Falkenmark, M., Karlberg, L., Corell, R.W., Fabry, V.J., Hansen, J. Walker, B., Liverman, D., Richardson, K., Crutzen, P., Foley, J.A., 2009. A safe operating space for humanity. Nature $461,472-475$.

Samuel-Fitwi, B., Wuertz, S., Schroeder, J.P., Schulz, C., 2012. Sustainability assessment tools to support aquaculture development. J. Clean. Prod. 32, 183-192.

Schuetze, T., Tjallingi, S.P., Correlje, A., Ryu, M., Graaf, R., van der Ven, F., 2008. Every Drop Counts: Environmentally Sound Technologies for Urban and Domestic Water Use Efficiency, first ed. United Nations Environment Programme, Nairobi, Kenya, p. 197.
Sengers, F., Wieczorek, A., Raven, R., 2016. Experimenting for sustainability transitions. A systematic literature review. Technol. Forecast. Soc. Change. https:// doi.org/10.1016/j.techfore.2016.08.031.

Sillani, S., Nassivera, F., 2015. Consumer behavior in choice of minimally processed vegetables and implications for marketing strategies. Trends Food Sci. Technol. 46 (2), 339-345.

Der Spiegel, 1984. Die ganze Stadt als Ur-Laube. Der Spieg. 39, 228-243. Available at. http://www.spiegel.de/spiegel/print/d-13512494.html. (Accessed 5 October 2016).

Suhl, J., Dannehl, D., Kloas, W., Baganz, D., Jobs, S., Scheibe, G., Schmidt, U., 2016 Advanced aquaponics: evaluation of intensive production in aquaponics vs. conventional hydroponics. Agric. Water Manag. 178, 225-344.

Sutherland, L.A. Peter, S., Zagata, L., 2015. Conceptualising multi-regime interactions: the role of the agriculture sector in renewable energy transitions. Res. Policy 44 (8), 1543-1554.

Suurs, RA.A., 2009. Motors of Sustainable Innovation. Towards a Theory of the Dynamics of Technological Innovation Systems. PhD Thesis. Utrecht University.

Tedesco, C., Petit, C., Billen, G., Garnier, J., Personne, E., 2017. Potential for recoupling production and consumption in peri-urban territories. The case-study of the Saclay plateau near Paris, France. Food Policy 69 (S), 35-45. https://doi.org/ 10.1016/j.foodpol.2017.03.006.

Tennant, D.R., Davidson, J., Day, A.J., 2014. Phytonutrient intakes in relation to European fruit and vegetable consumption patterns observed in different food surveys. Br. J. Nutr. 112, 1214-1225.

Thøgersen, J., 2017. Sustainable food consumption in the nexus between national context and private lifestyle. A multi-level study. Food Qual. Prefer. 55, 16-25.

Thurstan, R.H., Roberts, C.M., 2014. The past and future of fish consumption: can supplies meet healthy eating recommendations? Mar. Pollut. Bull. 89 (1-2), $5-11$.

Tyson, R.V., Treadwell, D.D., Simonne, E.H., 2011. Opportunities and challenges to sustainability in aquaponic systems. HortTechnology 21 (1), 7-13.

UN, 2012. United Nations. D.E.S.A. Population Division World Urbanization Prospects, the 2011 Revision, 2012. United Nations Department of Economic and Social Affairs/Population Division: New York, NY, USA, p. 318. Available at: http://www.un.org/en/development/desa/population/publications/pdf/urbani zation/WUP2011_Report.pdf. (Accessed 4 April 2017).

van der Goot, A.J., Pelgrom, P.J.M., Berghout, J.A.M., Geerts, M.E.J., Jankowiak, L. Hardt, N.A., Keijer, J., Schutyser, M.A.I., Nikiforidis, C.V., Boom, R.M., 2016 Concepts for further sustainable production of foods. J. Food Eng. 168 (S), $42-51$.

Van der Schans, JW. Wiskerke, JS.C, 2012. Urban agriculture in developed economies. In: Viljoen, A., Wiskerke, J.C.S. (Eds.), Sustainable Food Planning: Evolving Theory and Practice. Wageningen Academic Publishers, The Netherlands, p. 598.

Van Woensel, L., Archer, G., 2015. Ten technologies which could change our lives Potential impacts and policy implications. PE 527.417. In: EPRS - European Parliamentary Research Service. Scientific Foresight Unit (STOA), Brussels. Available at: http://www.ep.europa.eu/stoa/. (Accessed 6 September 2015).

Veludo, M., Hughes, A., Le Blan, B., 2012-2016. Introduction to aquaponics: a key to sustainable food production. In: Malmö Villarroel, M., Junge, R., Komives, T. König, B., Plaza, I., Bittsánszky, A., Joly, A. (Eds.), Survey of Aquaponics in Europe. Water, 8(10), S. 468. DOI: 10.3390/w8100468.

Villarroel, M., Junge, R., Komives, T., König, B., Plaza, I., Bittsánszky, A., Joly, A., 2016. Survey of aquaponics in Europe. Water 8 (10), S. 468. https://doi.org/10.3390/ w8100468.

Weber, K.M., Rohracher, H., 2012. Legitimizing research, technology and innovation policies for transformative change. Res. Policy 41 (6), 1037-1047.

Wellner, M., Knoop, M., Theuvsen, L., 2017. Der Markt für Obst und Gemüse. GJAE $66,82-96$.

York, R., Gossard, M.H., 2004. Cross-national meat and fish consumption. Exploring the effects of modernization and ecological context. Ecol. Econ. 48 (3), $293-302$. 